\title{
HR Differentiation
}

\section{A Theoretical Paper Integrating Co-Workers' Perspective and Context}

\section{Running Head: HR Differentiation}

\section{Yasin Rofcanin (corresponding author)}

Reader of Organizational Behavior and Human Resource Management

University of Bath, School of Management, the UK

E-Mail: y.rofcanin@bath.ac.uk

\section{Aykut Berber}

Professor of Management

University of Istanbul, School of Business

E-Mail: berber@istanbul.edu.tr

\section{Elise Marescaux}

Assistant Professor of HRM

IESEG School of Management (LEM-CNRS 9221), Lille, France

E-Mail: e.marescaux@ieseg.fr

\section{P. Matthijs Bal}

Professor of Responsible Management

Lincoln International Business School

University of Lincoln, Lincoln, UK

E-mail: $\underline{\text { mbal@lincoln.ac.uk }}$

\section{Farooq Mughal}

Lecturer (Assistant Professor)

University of Bath, School of Management, the UK

E-Mail: y.rofcanin@bath.ac.uk

f.mughal@bath.ac.uk

\section{Mine Afacan Findikli}

Associate Professor of Management (OB \& HRM)

Beykent University, Department of Business, Istanbul, Turkey

E-mail: minefindikli@beykent.edu.tr

There is no conflict of interest among co-authors.

This study did not receive any funding.

Acknowledgments: We would like to extent our genuine thanks to Editor in Chief, Anthony

McDonnell in particular, and three anonymous reviewers, who helped us improve the manuscript at every stage. 


\title{
HR Differentiation
}

\section{A Theoretical Paper Integrating Co-Workers' Perspective and Context}

\begin{abstract}
This paper conceptualizes 'HR differentiation' as a set of deliberate and differentiating HR practices across individuals within the organization to address employees' unique work needs and preferences as well as reward them for their input. Despite the importance of HR differentiation, research has mainly focused on the recipients of such practices, overlooking the consequences of HR differentiation from co-workers' perspective. This is a significant omission because a growing concern suggests that HR differentiation might be a double-edged sword, as the presumed positive effects might only be confined to employees benefiting from it. Taking a first step, this paper offers a conceptual model that explains how co-workers of a focal employee, who is entitled to an advantageous outcome through HR differentiation, are likely to react, either positively by showing contentment or negatively by showing anger, with behavioural consequences toward the focal employee and organisation. In so doing, we rely on deontic justice theory and explore contextual conditions at the individual and team level under which co-workers react. As a result, our model can inspire future research by adopting a broader and inclusive approach to HR differentiation, underlining the need for caution when implementing HR differentiation in a team setting.
\end{abstract}

Key Words: HR differentiation, justice, emotions, approach behaviours, avoidance behaviours. 


\section{INTRODUCTION}

Organizations are steadily increasing the room to individualize working conditions as a result of different trends, such as globalisation, the information economy, the democratization of workplaces and a decline in collective bargaining (Bal \& Dorenbosch, 2015). Employees welcome such opportunities for individual treatment as the workforce is becoming more diverse in terms of age, gender, and ethnicity, resulting in differing workplace needs (Liao et al., 2016); and is increasingly seeking to be treated as individuals, given their changing needs and preferences (Las Heras et al., 2017; Marescaux et al., 2013). This, in fact, has implications for human resource management (HRM) such that organisations are moving away from standardized HR practices, which apply to the entire organisation or a large group of employees, towards a more differentiated approach (e.g., Deloitte HR Trends, 2018). This trend is referred to as "HR differentiation", i.e. deliberately differentiating HR practices across individuals to address their work needs, preferences while acknowledging and rewarding them for their input (e.g., flexible schedules, telecommuting, i-deals; Marescaux et al., 2013). This conceptualisation underscores an inclusive approach to HR practices, as it recognises the unique values, proclivities and potential of each employee (McDonnell et al., 2017; Malik \& Singh, 2014), thus departing from an exclusive mindset where investments into employees are purely made to develop future managers and cater the needs of a select group of employees, such as A players or star employees (Björkman et al., 2018).

By nature, HR differentiation creates outcome differences between employees (Krausert, 2017; Marescaux et al., 2013). Employees are likely to react to such discrepancies, as social comparisons will raise questions concerning justice, triggering emotions, attitudes and behaviours (Cohen-Charash \& Spector, 2001; Gelens et al., 2013; Marescaux et al., 2013). Yet, surprisingly, this justice lens to HR differentiation has been overlooked in research so far. While Marescaux et al. (2013) hint to the importance of justice, they failed to consider the impact of 
outcome differences on affective organizational dimensions. Conceptualising HR differentiation as a holistic and inclusive process, the aim of this paper is to develop a conceptual model explaining how and when employees may react either negatively or positively to a focal employee's advantageous outcome, obtained through HR differentiation.

Firstly, we draw on deontic justice theory (i.e., DJT) to develop a conceptual model in which a focal employee's entitlement to an advantageous outcome acts as a justice event that elicits reactions among co-workers who are not entitled to the same outcome. DJT has been underexplored in HRM research, yet it is of particular relevance in advancing contemporary views of HRM theory and practice. Justice theories, to date, have mainly focused on personal interests and desires (Cropanzano et al., 2003), ignoring moral obligations to react to injustice. This is a significant omission because people may have other motives when reacting to injustice, above and beyond the pursuit of self-interests or social esteem (Tyler \& Blader, 2000). To provide a complete picture from co-workers' perspective, we ground our basic framework on DJT. The central tenet of this theory is that third parties can be motivated to respond to the perceived (mis)treatment of others out of moral obligations, above and beyond self-gains or interests (Folger \& Cropanzano, 1998; 2001), through a set of key deontic emotional reactions (i.e. anger and contentment; Folger et al., 2013). This subsequently results in deontic behaviours (i.e. approach and avoidance oriented behaviours) influencing the relational work dynamics. Moreover, we integrate equity theory (Adams, 1965) as a fundamental concept in explaining when co-workers are particularly inclined to react if an employee is entitled to an advantageous outcome. Specifically, co-workers are likely to react negatively (v.s. positively) when their own outcomes are particularly unfavourable (v.s. favourable) as opposed to the focal employee. In other words, the social comparison of outcomes (i.e., outcome favourability) triggered in the dyadic relationship between co-worker and focal employee will influence how co-workers react. 
Secondly, to capture the wider context in which HR differentiation occurs and impacts, we look beyond the dyadic relationship between co-worker and focal employee, by exploring the importance of the supervisor (who generally acts on behalf of the organisation to enable HR differentiation) and the team as a whole (in which employees are expected to function). Regarding the supervisor, we focus on co-workers' leader member exchange social comparisons with the focal employee (Vidyarthi et al., 2010; LMXSC), as a relational difference between co-worker and focal employee focused on the supervisor. At the team level, we explore the boundary role of (a) perceived motivational climate and (b) procedural \& interactional justice climate to acknowledge the wider team context in which HR differentiation occurs. The perceived motivational climate distinguishes between perceived mastery (e.g., open communication, knowledge sharing) and performance climate (e.g., closed communication, knowledge hiding). This is relevant because an underlying assumption of HR differentiation literature is that employees are expected to continue sharing benefits and knowledge gained from HR practices even when treated unequally (Bal \& Rousseau, 2015). This might not necessarily be the case since the team climate plays a decisive role in this regard. Our focus on procedural \& interactional climate perceptions highlight a key contextual element because coworkers may react either positively or negatively depending on the extent to which rules are followed fairly (Leventhal, 1976) and communication has been transparent (Greenberg, 1990) during the HR differentiation process.

Our first and main contribution lies in conceptualising HR differentiation as a broad and inclusive phenomenon composed of various HR practices that acknowledge the unique needs, preferences, performance and potential of each employee, thus going above and beyond rewarding only high performers or star employees (Swailes, 2013). In our conceptualisation of HR differentiation, we emphasise the need to consider emotional, relational and contextual factors affecting employees' workplace practices. This approach is novel as it recognises the 
premise that most tasks in an organisation are conducted through the works of employees who are not necessarily classified as talents or HIPOs (i.e., normal employees) and therefore it is not predisposed to catering the needs of only potential managers of the future (Delong \& Vijayaraghavan, 2003). Second, we disentangle the process of whether (and when) HR differentiation may trigger negative or positive reactions among co-workers taking note of the emotional, relational and contextual factors affecting employees. A focus on this process is important because an underlying assertion in HR differentiation literature has been that while the recipients of such practices demonstrate positive outcomes, such as strengthened commitment, HR differentiation is detrimental for co-workers because it damages social relations (Greenberg et al., 2004). By focusing on the boundary conditions, we discuss how HR differentiation can create a mutually win-win situation. Moreover, by taking into account key contextual variables (i.e. co-workers' outcome favorability, their relationship with their supervisor as well as the perceptions of work unit climate), we contextualize research on HR differentiation going beyond the dyadic relationship between employees. We develop concrete steps as to how our propositions can be tested in future and what line managers, along with HR units, can do to reap the best out of HR differentiation. In what follows, we develop our conceptual model (Figure 1).

Insert Figure 1 about here

\section{Theoretical Background}

Conceptualising HR Differentiation. Organisations increasingly recognise the value in differentiating their HR practices. This is largely driven by two trends: (1) From an employee viewpoint, the trend towards HR differentiation comes from the increasing desires of employees to secure work arrangements that meet their unique work needs and preferences (Call, Nyberg 
\& Thatcher, 2015). Due to diversity in age, gender and ethnicity, today's employees are characterized by individualized work patterns (Lepak, Takeuchi, \& Swart, 2011). Moreover, these employees are also more outspoken about their individual needs (Bal \& Lub, 2015). (2) From an organisational point of view, there is an increasing acknowledgment that each and every employee has unique talents, needs and contributions to the organisations (de Boeck et al., 2018; Garavan et al., 2012), a trend culminating towards a more inclusive approach of HR differentiation (McDonnell et al., 2017). Also, such an approach creates a potential gain in differentiating HR practices between employees because most work tasks are conducted interdependently in a team environment, suggesting that investing only in star employees or high performers may backfire (Garavan et al., 2012). Hence, we define HR differentiation as a broad and inclusive phenomenon, as a deliberate creation of outcome differences between employees by organisations or their representatives (e.g. HR departments and line managers) through the HR practices that address employees' unique needs, preferences, and inputs to the organisation. Examples of differentiated HR practices includes customized training and (career) developmental opportunities, flexi place, schedule or work arrangements (i.e., flexible work practices) as well as individualized reward packages.

The process behind the creation of these outcome differences can vary. Outcome differences can for example be created through individual bottom-up initiatives of employees in the form of one-off idiosyncratic deals (i-deals). This implies that employees negotiate special work arrangements with their employer, which are different from other employees and yet provide mutual benefits to all parties involved in the negotiation (Bal \& Rousseau, 2015; Rousseau, 2005). This typically involves aspects of a job for which line managers have the authorization power (e.g. a change in work schedule, training opportunities, bonuses, etc.). In contrast, it could also be a top-down process in which organisations - typically HR units deliberately create policies on HR differentiation, rather than deciding in an ad-hoc manner. In 
this case, HR differentiation tends to be authorized and encouraged by the HR representatives. For example, Bal and Dorenbosch (2015) refer to "individualized HRM" as a set of policies designed by HR departments to encourage managers to negotiate agreements with individual employees that satisfy their needs and preferences. Similarly, others refer to policies that allow for the "customization" of HR practices (e.g. Bal et al., 2015; Benko \& Weisberg, 2007). Regardless of the process behind the creation of HR differentiation, the common thread is that outcome differences are knowingly created between employees. In this paper, we explore how this affects employees.

\section{Proposition Development}

Co-Workers' Emotional Reactions to a Focal Employee's Entitlement to an Advantageous

\section{Outcome through HR Differentiation: Exploring the Boundary Conditions}

Deontic Justice Theory and Emotions. We draw on DJT as our theoretical backbone. Broadly speaking, justice scholars have mainly focused on two models of justice; instrumental and interpersonal models (Cropanzano et al., 2001). For instrumental models of justice, the focus is on goal achievement and personal goal realizations. Economic and self-interests are main drivers to achieve justice (Tyler \& Blader, 2000). Equity theory is an example of instrumental models, in which individuals seek to observe and maintain their own input/output balances in comparison to referent others. Interpersonal models of justice emphasize the key role of delivering clear and transparent communication to individuals, which is important because it signals one's social standing in their valued groups (Tyler \& Blader, 2000).

However, instrumental and interpersonal models of justice are unable to capture full reactions to injustice, especially from a third-party perspective. In fact, they focus on personal self-interests and desires, ignoring moral obligations. This is a key omission because people may have other motives and desires when reacting to injustice, above and beyond the pursuit of self-interests or social esteem (Cropanzano et al., 2003). To complete the story and provide 
a complete picture, we ground our basic framework on DJT and integrate it with instrumental and interpersonal models of justice (cf. infra).

The core tenet of DJT is that witnessing another's (mis)treatment engenders third party's sense of obligation to follow what they believe is fair and right (Folger \& Cropanzano, 2001). The theory underlines that observing (mis)treatment creates a deontic motivation through which third parties experience other-focused emotions. These emotions are related to the party who receives (mis)treatment and lead to approach or avoidance-oriented action tendencies, which reflect what third parties believe is just and fair (Folger, 2012). The theory underscores that the primary emotions which third parties experience from observing others' (mis)treatment are anger and contentment; these are moral emotions that are elicited by considering the welfare and interest of the other party (Folger, 2012). Furthermore, the theory underpins that positive emotions are usually associated with affect-driven adaptive behaviours that connect the individual with the source of (mis)treatment. On the contrary, negative emotions are usually associated with the tendency to withdraw, avoid and retaliate (Folger, 2012; Mitchell et al., 2015). Drawing on this logic, in the current study, we focus on moral reactions and the consequential approach, and avoidance behaviours of co-workers. Yet, how co-workers exactly react, will depend on the context in which the event occurs.

Co-Workers' Outcome Favorability. HR differentiation involves the distribution of valuable and rare HR related resources, which lead to perceived outcome differences. For example, while one employee may be awarded flexible work hours, another might receive more developmental support. Equity theory (Adams, 1965) suggests that such outcome differences are evaluated through a social comparison process. Specifically, employees will evaluate the favorability of their outcomes compared to the inputs they deliver (e.g., workload, work effort, performance and work hours) and especially compared to the outcomes other co-workers receive relative to their input (Carell \& Dittrich, 1978). This comparison usually occurs among 
employees working in the same team, who are comparable to the focal employee in terms of status or role, with whom they interact frequently and who have created a history of a working relationship (Buunk \& Gibbons, 2007). This outcome favourability (defined as a positive or negative outcome compared to others) subsequently triggers emotional, attitudinal and behavioural reactions, as it sets in motion questions concerning fairness (Barsky et al., 2011; Marescaux et al., 2013; Skitka et al., 2003)

As such, in the event of a focal employee receiving an advantageous outcome through HR differentiation, a social comparison process will be set in motion. This implies that coworkers will evaluate the favourability of this outcome compared to their own. Depending on this perception of outcome favourability (either positive or negative), co-workers might react differently. When co-workers perceive unfavourable outcomes compared to the focal employee (i.e., being in a disadvantaged position), they will react negatively through feelings of anger. This is likely because perceptions of outcome unfavourability do not align with their beliefs of what should be fair and right; leading to disappointment (Barsade \& Gibson, 2007), generating feelings of anger. On the contrary, co-workers' perceptions of favourable outcomes are likely to coincide with their beliefs of what should be equitable; leading to feelings of contentment (Kristof-Brown \& Stevens, 2001).

Proposition 1(a): Co-workers' perceptions of outcome unfavourability amplify the positive association between a focal employee's entitlement to an advantageous outcome through HR differentiation and co-workers' feeling of anger towards the focal employee and the organisation.

Proposition 1(b): Co-workers' perceptions of outcome favourability amplify the positive association between a focal employee's entitlement to an advantageous outcome through HR differentiation and co-workers' feeling of contentment towards the focal employee and the organisation. 
Co-workers' Perceptions of LMXSC: LMX social comparison (LMXSC) refers to a subjective comparison between one's own LMX and that of one's co-workers and demonstrates one's relative standing in terms of the relationship quality with the supervisor (Viyarthi et al., 2010). Employees with high LMXSC perceptions perceive their relationships to be of better quality (i.e., higher levels of trust, respect and support from managers) than their co-workers'. In contrast, employees with low LMXSC perceive that their managers have a higher quality relationship with co-workers as opposed to themselves. We propose that co-workers will react more negatively in the event of an employee receiving an advantageous outcome by displaying anger when their perception of LMXSC is low. This is likely because co-workers with low perceptions of LMXSC are not likely to believe that their manager values them and considers them worthy of investment in terms of HR practices (e.g., Gelens et al., 2013). Moreover, these employees are not likely to trust their managers to be fair in decisions concerning HR differentiation (Erdogan \& Bauer, 2010). Their current LMXSC shape their perceptions of future psychological contracts, diminishing their expectations from their managers $(\mathrm{Ng} \&$ Feldman, 2012; Roehling, 2008). As a result, in the event of another employee receiving an advantageous outcome, they react more strongly through anger.

On the contrary, employees with high perceptions of LMXSC believe that they have a good standing in the eyes of their managers, and they acknowledge that their managers are likely to invest in them as they did for the focal employee. Moreover, high perceptions of LMXSC are more likely to lead co-workers to trust their managers in their decisions concerning HR differentiation (Erdogan \& Bauer, 2010). Overall, their current LMXSC shape their perceptions of future psychological contracts, increasing their expectations from their managers (Ng \& Feldman, 2012). As a result, in the event of another employee receiving an advantageous outcome, they react positively through contentment.

Proposition 2(a): Co-workers' perceptions of low LMXSC amplifies the positive 
association between a focal employee's entitlement to an advantageous outcome through HR differentiation and co-workers' feeling of anger towards the focal employee and the organisation.

Proposition 2(b): Co-workers' perceptions of high LMXSC amplifies the positive association between a focal employee's entitlement to an advantageous outcome through HR differentiation and co-workers' feeling of contentment towards the focal employee and the organisation.

Perceived Unit Climate: In a work unit characterized by mastery climate; collaboration and cooperation among team members, learning, mastery and skill development are supported and emphasized (Ames et al., 2002). A perception of shared fate and trust develops, encouraging supportive behaviours whereby each team member looks out for the interests of other team members in addition to his or her own (Beersma et al., 2003). Thereby, the insights gained and experiences learned by one team member is shared with other team members so that other team members can benefit from his or her knowledge accumulation (Johnson et al., 2006). These behaviours reduce employees' motives for knowledge hiding. We note that knowledge hiding is similar to knowledge guarding in that both are characterized by behaviours aimed at withholding knowledge from other employees (Hislop, 2003). However, there is a key difference between the two concepts: knowledge hiding refers to intentional concealment of knowledge requested from other employees in a work setting while knowledge guarding refers to the accumulation of knowledge that may or may not be shared with other employees in the future (Connelly et al., 2012).

In the event of an employee receiving a more advantageous outcome, a mastery climate will elicit more positive reactions from co-workers for several reasons. Firstly, it will make it more likely for the focal employee to share this information with team members as the norms of information sharing and cooperation would lead the group to distrust him/her should he/she 
hide this information. Secondly, information exchange is not only supported among peers but also between hierarchies as well (Nerstad et al., 2013). This indicates that rules, policies and procedures are not imposed in a top-down manner by managers but they co-evolve through the input of everyone (Ames, 1992). In other words, in the context of providing a focal employee with a more advantageous outcome, all team members are likely to have been involved in the process and been encouraged to speak up to prevent possible inconsistencies or any unethical conducts, for instance when it comes to deciding who is entitled to specific outcomes and why. Moreover, since self-development and investment in skills are key criteria for success in a mastery climate (Beersma et al., 2003), such a climate makes it more likely for co-workers to expect to receive similar outcomes in the future. This reduces the likelihood of a competitive comparison between the focal employee and rest of the team members (Matzler \& Müller, 2011). Finally, co-workers are likely to acknowledge that objective criteria (e.g., performance, contribution to team cohesiveness) are used when a focal employee receives a more advantageous outcome. Norms related to communication (e.g., information exchange, dignity, respect, openness) and criteria for success (sharing of knowledge, skill upgrade, investment in development opportunities, mastery orientation) reduce the contrasts between the recipient of HR differentiation and rest of the team members, positively influencing co-workers' emotional reactions towards a focal employee.

Research from team cohesion support our arguments. Teams high on cohesiveness are characterised by open communication and trust. Team goals and norms are clear and implemented fairly. The underlying assumption here is that to maximize team goal achievement, team members need to achieve a level of trust by reducing individual fears of rejection by the group (Chang et al., 2003). These characteristics support the notion that members of cohesive teams expect each member to contribute to the achievement of team goals and encourage staying away from personal friction as well as frustration (von Glinow et al., 
2004). These defining features of cohesive teams suggest that once a member of a team is provided with differentiated HR practice, if s/he is committed to the achievement of team goals and thus does not experience conflict with others, other team members are likely to be supportive of HR differentiation.

Information sharing, open communication and skill development are features of mastery climate and trust - collaboration features of cohesive teams constitute the bases of our third proposition (3a).

Proposition 3(a): A perceived mastery climate amplifies the positive association between a focal employee's entitlement to an advantageous outcome through HR differentiation and co-workers' feeling of contentment towards the focal employee.

On the contrary, in a work unit characterized by a performance climate, forced social comparison and intra-team competitions are emphasized (Roberts, 2012). Normative criteria define success and there is an inherent focus on outperforming others (Pensgaard \& Roberts, 2002). Team members are forced to compete with each other, hide insights learned and experienced gained from others. Thereby, hiding knowledge is expected to give a focal employee a competitive edge, which, in a performance climate, is seen as the most important objective (Cumming, Smoll, Smith, \& Grossbard, 2007). Where information hiding is a norm (Nerstad et al., 2013); distrust, negative social interactions and maladaptive behaviours (e.g., political games) prevail. In the context of providing a focal employee with a differentiated HR arrangement, only the focal employee and their supervisor are likely to be involved in this process while others are alienated, discouraged to speak up, leading to perceptions of favouritism among the rest of the team members.

Furthermore, given the criteria for success is outperforming others, team members are not going to expect to receive similar outcomes in the future because doing so is against the norm of a competitive (teeth-to-teeth) work unit culture (Chang et al., 2003). Norms related to 
communication (e.g., information hiding, distrust, forced social comparison) and criteria for success (intra team competition, shady deals, favouritism, under-the-table deals) widen the contrasts between the recipient of an advantageous outcome through HR differentiation and coworkers, leading to increased anger among co-workers. Research from team cohesion support our arguments: Teams low on cohesiveness are likely to display conflict. While these conflicts may be constructive, most of the times they emerge from the lack of trust, supportiveness and open communication among team members. Put simply, low cohesiveness is usually characterized by lack of shared goals, unclear norms, and thus high pressure to outperform team members, observed usually in the form of information hiding (Tekleab et al., 2009). These characteristics of teams rating low on cohesiveness suggest that once a team member is provided with a differentiated HR practice, other members are less likely to be supportive due to social comparisons, the pressure to outperform and internal competitive dynamics.

Information hiding, forced social comparison and intra-team competition features of performance climate and lack of trust - collaboration features of teams low in cohesiveness constitute the basis of our third proposition (3b).

Proposition 3(b): A perceived performance climate amplifies the positive association between a focal employee's entitlement to an advantageous outcome through HR differentiation and co-workers' feeling of anger towards the focal employee.

Perceived Procedural and Interactional Justice. Perceived procedural justice refers to the fairness of decision-making processes - it is evaluated by whether procedures are consistent, accurate, unbiased, correctable, and provide mechanisms for voice and input (Leventhal, 1976). Interactional justice is composed of two dimensions: Informational justice-the perceived adequacy of explanations - is fostered by accurate and detailed explanations for key events (Bies \& Moag, 1986; Greenberg, 1993). Interpersonal justice-the perceived sensitivity of interpersonal communication-is fostered by treating employees respectfully (Greenberg, 
1993).

We propose that in work units characterised by high procedural justice perceptions, coworker reactions to a focal employee's HR differentiation is likely be positive. According to fairness theory (Folger \& Cropanzano, 1998), when procedures are followed fairly in providing a focal employee with differentiated HR practices, co-workers will find it difficult to imagine outcomes that are better than their current outcomes, making them less inclined to show negative reactions and behaviours (Folger, 1993). Furthermore, consistent and fair procedures will signal to co-workers that their needs, preferences and outcomes will be evaluated favourably and be predictable in the future, making co-workers less likely to show anger and avoidance-oriented behaviours (Thibault \& Walker, 1975). On the contrary, in work units characterised by low procedural fairness perceptions, co-workers are likely to react negatively to a focal employee's HR differentiation. This is because co-workers are likely to perceive that fair procedures are not followed in providing a focal employee with differentiated HR practices, raising perceptions of favouritism, (Folger \& Cropanzano, 1998). Furthermore, in such a work unit, co-workers are likely to imagine that in the future, their requests for similar deals will not be evaluated favourably and in a just way by decision makers, reducing their trust and triggering negative emotions (Folger et al., 2002).

Similarly, we propose that co-workers' interactional justice perceptions moderate the impact of co-worker reactions in such a way that when perceived interactional justice perceptions are high (v.s. low), co-workers are likely to react positively (v.s. negatively) to a focal employee's HR differentiation. When managers provide adequate and clear explanations as to why a focal employee is provided with a differentiated HR practice and others are not, coworkers are likely to trust their managers and believe that they would not obtain better outcomes than their current ones. Furthermore, clear and consistent explanations to co-workers about a focal employee's differentiated HR practices is likely to foster co-workers' experiences of high 
self-esteem, thus making it less likely for co-workers to be affected negatively by a specific event, i.e., HR differentiation (Lind \& Tyler, 1988). On the contrary, when co-workers do not receive any information (or clues) as to why they are excluded from differentiated HR practices while some are entitled to them; they are less likely to trust their managers and will experience low self-esteem. Thus, co-workers are likely to show anger towards a focal employee who is entitled to HR differentiation (e.g., Gelens et al., 2014). We thus propose:

Proposition 4 (a): High perceived procedural and interactional justice amplifies the positive association between a focal employee's entitlement to an advantageous outcome through HR differentiation and co-workers' feeling of contentment towards the focal employee.

Proposition 4 (b): Low perceived procedural and interactional justice amplifies the positive association between a focal employee's entitlement to an advantageous outcome through HR differentiation and co-workers' feeling of anger towards the focal employee.

Interaction between unit climate and justice. Finally, we argue that the unit climate interacts with perceived procedural/interactional justice in its effect on co-workers' emotions of anger and contentment. Specifically, when the organization, through HR differentiation, allocates advantageous outcomes to employees in a procedurally and interactionally fair way, this likely reinforces the contentment co-workers feel in a mastery climate. This is because such justice perceptions fit with the essential characteristics of a mastery climate by further supporting the exchange of information, giving employees a voice in decision-making, fostering trust, and clarifying the objective criteria that are used for allocating outcomes (Ames, 1992; Nerstad et al., 2013). Hence, the favourable impact of a mastery climate on contentment will be amplified. In contrast, procedural and interactional unfairness conflicts with a mastery climate, which creates counteracting forces, thwarting the positive impact of a mastery climate 
on contentment. Similarly, we would argue that procedural/interactional justice matters for a performance climate in that it can buffer the negative effect on co-workers' anger. By allocating advantageous outcomes in a procedurally and interactionally just manner, organizations make it clear to co-workers how they can achieve more favourable outcomes in the future by communicating the objective criteria and procedures used. This will downplay perceptions of favouritism among co-workers as well as give co-workers the idea that they can expect to receive similar outcomes in the future, should they qualify, which subsequently reduces anger. In contrast, perceptions of procedural/interactional unfairness further exacerbate the drawbacks from a performance climate, i.e. competition, favouritism and little reasons to believe coworkers will receive a similar outcome in the future. Hence, anger is further amplified.

Proposition 5(a): Perceptions of procedural/interactional justice amplify the positive association between a perceived mastery climate and co-workers' feelings of contentment when a focal employee is entitled to an advantageous outcome through HR differentiation.

Propositions 5 (b): Perceptions of procedural/interactional justice weaken the positive association between a perceived performance climate and co-workers' feelings of anger when a focal employee is entitled to an advantageous outcome through HR differentiation.

Behavioural reactions as a result of emotions. DJT argues that deontic emotions (anger and contentment) are key in explaining how and why individuals react to justice issues arising from others' treatment, providing insight into the types of behavioural reactions individuals are likely to have (Breugelmans \& De Cremer, 2007). Individuals who are experiencing contentment might feel compelled to further connect or engage with the source of the contentment (De Cremer \& van den Bos, 2007) while individuals who are experiencing anger, might feel the urge to react against the source of the anger (e.g., retaliate). This is likely because positive emotions expand individuals' thought-action repertoires while negative emotions limit them, triggering certain behaviours (e.g., helping when experiencing positive 
emotions; withdrawal when experiencing negative emotions; Fredrickson, 2001). In relation to our propositions, positive emotions emanating from co-workers' evaluation of a focal employee's entitlement to an advantageous outcome (under certain conditions as discussed above), are likely to trigger approach-oriented behaviours that connect employees to their work environments, such as engaging in organisational citizenship behaviours (Fredrickson, 2001). On the contrary, co-workers' feelings of anger are likely to lead them to withdraw from their work environments, such as showing withdrawal or retaliation behaviours. Our last proposition is as below:

Proposition 6 (a): Co-workers' feeling of contentment is positively associated with their approach oriented behaviours towards the focal employee (e.g., OCB-I) and the organisation (e.g., OCB-O).

Proposition 6 (b): Co-workers' feeling of anger is positively associated with their avoidance oriented behaviours towards the focal employee (e.g., retaliation) and the organisation (e.g., psychological withdrawal).

\section{Discussion}

\section{Theoretical Contributions}

In this paper, we focus on the differential implementation of HR practices to address employee work needs, ensuring that employees are treated individually and thereby allocating resources in an efficient and effective manner. Recent meta-analyses on i-deals (Liao et al., 2016), flexible work practices (Allen et al., 2012) and talent management (McDonnell et al., 2017) demonstrate the growing need, across countries, industries and job groups, for the differentiation of HR practices. While the benefits of HR differentiation seem plausible from recipients' perspective, whether and how HR differentiation can be beneficial (or not) for coworkers remains absent from extent literature. Our main, and first, contribution has been in reconceptualising HR differentiation as a broad and inclusive approach, which must take note of 
the emotional, relational and contextual factors affecting employees' workplace practices. Such a focus is novel and important in that it goes beyond research which has almost equated HR differentiation with talent management (Krausert, 2017), or i-deals (Liao et al., 2016). This could be concerning because only a select group of employees tend to benefit from such practices (e.g., HIPOs, A players, i-dealers, talents; Huseli et al., 2005) while the remaining are usually excluded (Swailes, 2013). Besides, such an exclusive approach to employee management is costly and aim to train and motivate predominantly the managers of future (Garavan et al., 2012). As such, this perspective overlooks the unique values, needs and talents of each employee and thus, does not acknowledge the premise that most tasks in an organisation are conducted through the works of employees who are not necessarily classified as talents or HIPOs (i.e., normal employees). Indeed, as noted by Delong and Vijayaraghavan (2003, p. 96), “...our understandable fascination with star performers can lure us into the dangerous trap of underestimating the vital importance of the supporting actors". Our conceptualisation of HR differentiation, thus, aims to offer a holistic view by considering the peculiar characteristics of employees.

Our second contribution is in our focus on understanding whether and when HR differentiation may invoke either negative or positive reactions among co-workers. This is important because an underlying assertion in HR differentiation literature has been that while such practices may have positive impact on the recipients' work outcomes and motivation (e.g., Marescaux et al., 2013), they may have negative social consequences if they strain relationships within a team (Greenberg et al., 2004). Indirectly supporting this argument, few recent studies have started questioning the double-edged side of differentiated HR practices: A recent study by $\mathrm{Ng}$ (2017) integrated co-worker reactions to a focal employee's experiences of i-deals to understand the potential negative responses towards such deals within a team. A key finding is that the perceptions of a competitive climate leads co-workers to react negatively (i.e., counter- 
productive work behaviours) while the perceptions of supportive climate triggers positive reactions among co-workers (i.e., helping and socially connecting behaviours). We contribute to these debates by exploring and offering a complete picture of instances when $\mathrm{HR}$ differentiation can result in a mutually win-win strategy and when it needs to be avoided.

Our third contribution lies in discussing key contextual conditions to understand when the consequence of HR differentiation may be positive and negative. In so doing, at individual employee level, we focused on co-workers' outcome favourability and LMXSC perceptions, which emphasize the triadic relationships among focal employee, co-workers and their line managers. Understanding the individual level contextual conditions is important to map the consequences of HR differentiation, which do not happen in isolation considering the strong interdependent relations between a recipient of HR differentiation (who benefits from it), their supervisor (who typically implements and communicates it) and co-workers (Clinton \& Guest, 2013).

In a related vein, a further contribution of our study relates to our focus on the perceptions of motivational (i.e., mastery vs. performance orientation) and justice (i.e., procedural and interactional) climates. Regarding the former, we discussed how knowledge hiding and sharing shape co-workers' emotional reactions. Relating knowledge hiding (vs. sharing) to HR differentiation is novel, given most research has treated distrust (Wang \& Noe, 2010), interpersonal justice (Donovan, Drasgow, \& Munson, 1998) or justice climate (Colquitt, Noe \& Jackson, 2002) as antecedents to these behaviours (Connelly et al., 2012). Regarding the latter, we discuss how transparent communication (interactional justice) and procedural conformity (procedural justice) may alleviate the potential negative reactions of co-workers, reducing their feelings of uncertainty and increasing their trust to the organisation (or the representative of the organisation; Cheshire, Gerbasi, \& Cook, 2010). This perspective is important because, justice research suggest that people are prone to fairness judgments in 
situations of social interdependence. As such, when people are exposed to an authority who has the power to communicate and decide on the distribution of certain resources (providing differentiation), thoughts of potential exploitation and exclusion come into play. Thus, breeding a climate where information is communicated transparently, and procedures are followed, may eventually alleviate the potential negative ramifications of HR differentiation for co-workers (Boeck et al., 2018). More broadly, our conceptual model integrates unit level constructs that are complimentary in nature (e.g. motivational climate being outcome oriented and goal driven, about knowledge sharing and hiding dynamics; fairness climate being more relational and cognitive oriented, about future expectations), yet captures different components of the consequences of HR differentiation.

\section{Future Research Agenda}

Below, we discuss how studies in the future may empirically test the propositions deriving from our conceptual model.

\section{Conceptualisation of HR differentiation:}

Since there is no consensus on the definition of HR differentiation, we suggest that as a first step, future studies conduct qualitative studies to explore the meaning, features and dimensions of HR differentiation. A potential way is conducting in-depth interviews with HR executives as well as line managers (as implementers of such practices). A second potential way is participant observation, such as spending time in HR departments, closely collaborating with them and observation all of which may reveal the criteria of HR differentiation. The use of qualitative approach, as a first step, enables exploring the concept of HR differentiation in depth and arriving at a fine-tuned definition. In addition to clarifying the conceptualisation, adoption of qualitative designs will enable researchers to see in which sectors and jobs HR differentiation is likely to be observed (e.g., consultancy, free-lance jobs or senior level positions) and not observed (e.g., production and industry; non-senior level positions and jobs). 
Once the definition and dimensions of HR differentiation are determined, a second way is to explore and ascertain different dimensionality of HR differentiation (e.g., i-deals, flexible work practices, initiatives for non-work life of employees). Here, the aim should be to map out the construct of HR differentiation and define the sub-dimensions through which organisations may manage its differential implementation.

\section{Testing the Propositions of HR Differentiation:}

Three key issues need to be considered when testing the propositions in relation to HR differentiation: Time, the measurement of reactions of co-workers and multi-level (nested) structure of reporting relationships among employees, co-workers and line managers. Researchers (e.g., Liao et al., 2009) support that it takes some time for the impact of HR practices on employees to materialize; this necessitates using longitudinal research design which increases rigor in the analysis (Boxall, Purcell, \& Wright, 2007). Thus, in relation to testing our propositions, we suggest using time intervals (e.g., six months; Peccei \& van de Voorde, 2016) between independent, mediators and outcome variables.

A second issue is the reactions of co-workers. Co-workers who are excluded from differentiated HR practices may be reluctant to reflect on and discuss their emotions due to various reasons (fear of losing jobs, reprimands from line managers or cultural norms). We suggest creating excerpts/scenarios depicting a case of HR differentiation where excluded employees are more likely to feel confident in responding (e.g., critical incident technique). In these scenario's, different factors that are thought to influence respondents can be manipulated (e.g. outcome favourability, LMXSC and team climate) which allows researchers to causally test the impact of such factors (Wason et al., 2002).

A third issue is the multi-level structure of our proposed associations (Peccei \& van de Voorde, 2016). In testing the impact of our contextual conditions, the nested structure of the data should be taken into account. In particular, regarding LMX social comparison, more than 
one subordinate may report to the same line manager, which will necessitate nesting of subordinates into the same supervisor. Perceived unit climate and procedural - interactional justice climate represents constructs at the team level. Employees could be asked for their overall perceptions at the team level (e.g., in our team, collaboration among peers is supported; Chen et al., 2005) and then in testing the moderating impact of these two constructs; centring around units or teams is suggested (Raudenbush \& Bryk, 2002). Outcome favourability, on the other hand, is built on individuals' perceptions; thus, it does not require nesting or team-level centring.

Our suggested scenario-based, multi-level and longitudinal designs can be tested using cross-level moderated mediation procedures. An advantage of this approach is that it enables testing the overall model, thus adds to the strength and rigor of findings. If the data is collected from dyads (e.g., focal employee and co-workers), the actor-partner interdependence model (i.e., Kenny et al., 2006; APIM;) can be an appropriate strategy of analysis as it deals with the violations of statistical independence and investigates the dyadic effects. Specifically, APIM allows examining how an individual's predictor variable simultaneously and independently relates to his or her own criterion variable (actor effect), and to his or her partner's criterion variable (partner effect).

From a theoretical perspective, other related constructs and frameworks in relation to perceived motivational climate may constitute further research avenues. One such framework is unit goal orientation. It manifests itself in the form of learning orientation and competition orientation (Alexander \& van Knippenberg, 2014). Units with high learning orientation are good at adapting work processes to changing circumstances (e.g., LePine, 2005; Porter, 2005). In competitive climates, employees seek to obtain organisational rewards as determined by their performance relative to their peers (Kohn, 1992). Competitive climates are further described as being prove-oriented, in which units compete with other units to gain recognition and financial 
rewards; or avoid oriented, in which teams seek to avoid negative judgments to maintain appearance of competence (Mehta et al., 2009). Adoption of such a framework may extend our model to inter-unit level of analysis.

\section{Practical Implications}

This study raises the possibility that, despite its presumed benefits, HR differentiation might not always be sustainable. By shedding light on the potential, unfavourable, emotional reactions of co-workers and the boundary conditions that yield such reactions, our model guides HR managers in making decisions carefully, with short term and long term costs in mind. The costs of co-worker reactions might outweigh the benefits of HR differentiation. In relation to co-workers' perceived outcome (un) favourability, an important way to tackle potential negative reactions of co-workers is to provide explicit guidelines and conduct open communications with employees regarding why they are not entitled to HR differentiation while others are. With regards to LMX social comparisons, supervisors can play a role by ensuring that co-workers enjoy a high-quality relationship with them, i.e. characterized by trust, respect and support, even when their tangible outcomes are lower than other employees. Additionally, the team climate should be motivational in nature to ensure positive reactions. Finally, it is crucial that HR managers provide transparent principles for the use of differentiated HR practices and communicate them openly to everyone, which is especially important in cases where information to co-workers cannot be provided. Accordingly, HR managers need to be trained on how to describe and communicate HR differentiation practices not only to its recipients but also to co-workers, emphasizing the ways in which they are justified and granted. Explaining why others are not entitled to such practices might diminish co-workers' potentially negative consequences (e.g., Bjorkman et al., 2013). 


\section{REFERENCES}

Adams, J.S. (1965). 'Inequity in social exchange'. In L. Berkowitz (ed.), Advances in Experimental Social Psychology, Vol. 2. New York: Academic Press, pp.267-99.

Allen, T.D., Johnson, R.C., Kiburz, K.M., \& Shockley, K.M. (2013) Work-family conflict and flexible work arrangements: Deconstructing flexibility. Personnel Psychology 66(2): $345-376$.

Ames, C. (1992). Achievement goals, motivational cli- mate, and motivational processes. In G. C. Roberts (Ed.), Motivation in sport and exercise: 161-176. Champaign, IL: Human Kinetics Books.

Bal, P.M. \& Dorenbosch, L. (2015). Age-related differences in the relations between individualized HRM and organizational performance: A large-scale employer survey. Human Resource Management Journal, 25, 41-61.

Bal, P.M. \& Lub, X.D. (2015). Individualization of work arrangements: A contextualized perspective on the rise and use of i-deals. In P.M. Bal \& D.M. Rousseau (eds), Idiosyncratic Deals between Employees and Organizations: Conceptual Issues, Applications and the Role of Co-workers. Oxford: Taylor \& Francis Group, pp.52-65.

Bal, P.M. \& Rousseau, D.M. (2015). Idiosyncratic Deals between Employees and Organizations: Conceptual Issues, Applications and the Role of Co-workers. Oxford: Taylor \& Francis Group.

Barsade, S.G., \& Gibson, D.E. (2007). Why does affect matter in organizations? Academy of Management Perspectives, 21, 36-59. 
Barsky, A., Kaplan, S.A., \& Beal, D.J. (2011). Just feelings? The role of affect in the formation of organizational fairness judgments. Journal of Management, 37(1), 248279.

Beersma, B., Hollenbeck, J. R., Humphrey, S. E., Moon, H., Conlon, D. E., \& Ilgen, D. R. (2003). Cooperation, competition, and team performance: Toward a contingency approach. Academy of Management Journal, 46, 572-590.

Bies, R. J., \& Moag, J. F. (1986). Interactional justice: Communication criteria of fairness. In R. J. Lewicki, B. H. Sheppard, \& M. H. Bazerman (Eds.), Research on negotiations in organizations (pp. 43-55). Greenwich, CT: JAI Press.

Bjorkman, I., Ehrnrooth, M., Hogllund, M., Makela, K., Smale, A., \& Sumelius, J. (2013). Talent or not? Employee reactions to talent identification. Human Resource Management, 52(2), 195-214.

Boxall, P. F., Purcell, J., \& Wright, P.M. (2007). The Oxford handbook of human resource management: scope, analysis and significance. In P. F. Boxall, J. Purcell, \& P.M. Wright (Eds.), The Oxford handbook of human resource management (pp. 1-18). New York: Oxford University Press Inc.

Breugelmans, S., \& De Cremer, D. (2007). The role of emotions in cross-cultural justice research. In D. De Cremer (Ed.), Advances in the psychology of justice and affect: 85106. Charlotte, NC: Information Age.

Buunk, A.P., \& Gibbons, F.X. (2007). Social comparison: The end of a theory and the emergence of a field. Organizational Behavior and Human Decision Processes, 102, 3- 21.

Benko, C. \& Weisberg, A. (2007). Mass Career Customization: Aligning the Workplace with Today's Nontraditional Workforce. Boston, MA: Harvard Business School Press. 
Call, M.L., Nyberg, A.J. \& Thatcher, S.M.B. (2015). Stargazing: An integrative conceptual review, theoretical reconciliation, and extension for star employee research. Journal of Applied Psychology, 100, 623-40.

Carrell, M.R. \& Dittrich, J.E. (1978). Equity theory: the recent literature, methodological considerations and new directions. Academy of Management Review, 3(2), 202-210. DOI: 10.5465/AMR.1978.4294844

Cerne, M., Nerstad, C.G.L., Dysvik, A., \& Skerlavaj, M. (2014). What does around comes around: Knowledge hiding, perceived motivational climate and creativity. Academy of Management Journal, 57, 172-192. DOI: 10.5465/amj.2012.0122

Clinton, M. \& Guest, D.E. (2013). Testing universalistic and contingency HRM assumptions across job levels. Personnel Review, 42, 529-51.

Cohen-Charash, Y., \& Spector, P.E. (2001). The role of justice in organizations: A metaanalysis. Organizational behavior and human decision processes, 86(2), 278-321.

Collins, A. M., Cartwright, S., \& Hislop, D. (2013). Homeworking: negotiating the psychological contract. Human Resource Management Journal, 23: 211-225.

Colquitt, J. A., Noe, R. A., \& Jackson, C. L. (2002). Justice in teams, antecedents and consequences of procedural justice climate. Personnel Psychology, 55, 83 -109.

Collings, D.G. \& Mellahi, K. (2009). Strategic talent management: A review and research agenda. Human Resource Management Review, 19(4), 304-13.

Connelly, C.E., Zweig, D., Webster, J. \& Trougakos, J.P. (2012). Knowledge hiding in Organizations. Journal of Organizational Behavior, 33 (1), 64-88.

De Boeck, G., Meyers, M.C. \& Dries, N. (2018). Employee reactions to talent management: Assumptions versus evidence. Journal of Organizational Behavior, 39, 199-213.

De Cremer, D., \& van den Bos, K. (2007). Justice and feelings: Toward a new era in justice research. Social Justice Research, 20, 1-9. 
Deloitte HR Trends (2018). Available on-line at:

https://www2.deloitte.com/content/dam/insights/us/articles/HCTrends2018/2018HCtrends_Rise-of-the-social-enterprise.pdf

Donovan, M.A., Drasgow, F., \& Munson, L.J. (1998). The perceptions of fair interpersonal treatment scale: Development and validation of a measure of interpersonal treatment in the workplace. Journal of Applied Psychology, 83, 683-692.

Dries, N. \& Gieter, S.D. (2014). Information asymmetry in high potential programs: A potential risk for psychological contract breach. Personnel Review, 43(1), 136-162.

Ehrnrooth M, Björkman I, Mäkelä K, Smale A, Sumelius J, Taimitarha S. (2018) Talent responses to talent status awareness-Not a question of simple reciprocation. Human Resource Management Journal, 1-19. https://doi.org/10.1111/1748- 8583.12190.

Erdogan, B., \& Bauer, T.N. (2010). Differentiated leader-member exchanges: The buffering role of justice climate. Journal of Applied Psychology, 95, 1104-1120.

Folger, R. \& Cropanzano, R. (1998). Organizational Justice and Human Resource Management. Thousand Oaks, CA: Sage.

Folger, R. \& Cropanzano, R. (2001). Fairness theory: Justice as accountability. In J.

Greenberg \& R. Cropanzano (eds), Advances in Organizational Justice. Stanford, CA: Stanford University Press, pp.1-55.

Folger, R., \& Skarlicki, D. P. (2001). Fairness as a dependent variable: Why tough times can lead to bad management. In R. Cropanzano (Ed.), Justice in the workplace: From theory to practice (pp. 97-118). Mah-wah, NJ: Erlbaum.

Folger, R. (2012). Deonance: Behavioral ethics and moral obligation. In D. DeCremer \& A. Tenbrunsel (Eds.), Behavioral business ethics: Ideas on an emerging field (pp. 123142). London, United Kingdom: Taylor \& Francis. 
Folger, R., Ganegoda, D.B., Rice, D.B., Taylor, R., \& Wo, D.X.H. (2013). Bounded autonomy and behavioral ethics: Deonance and reactance as competing motives. Human Relations, 66, 905-924.

Gelens, J., Dries, N., Hofmans, J. \& Pepermans, R. (2013). The role of perceived organizational justice in shaping outcomes of talent management: A research study. Human Resource Management Review, 23, 341-53.

Gelens, J., Hofmans, J., Dries, N., \& Pepermans, R. (2014). Talent management and organisational justice: Employee reactions to high potential identification. Human Resource Management Journal, 24, 159-175.

Greenberg, J., Roberge, M.E., Ho, V.T. \& Rousseau, D. (2004). Fairness as an “i-deal”: Justice in under-the-table employment arrangements. In J. J. Martochio (ed.), Research in Personnel and Human Resources Management. Oxford: JAI Press/Elsevier Science, pp.1-34.

Greenberg, J. (1990). Organizational justice: Yesterday, today and tomorrow. Journal of Management, 16, 399-432.

Johnson, M. D., Hollenbeck, J. R., Humphrey, S. E., Ilgen, D. R., Jundt, D., \& Meyer, C. J. (2006). Cutthroat cooperation: Asymmetrical adaptation to changes in team reward structures. Academy of Management Journal, 49, 103-119.

Hislop, D. (2003). Linking human resource management and knowledge management via commitment: A review and research agenda. Employee Relations, 25, 182-202.

Hornung, S., Rousseau, D.M., \& Glaser, J. (2008). Creating flexible work arrangements through idiosyncratic deals. Journal of Applied Psychology, 93(3), 655-664.

Krausert, A. (2017). HR differentiation between professional and managerial employees: Broadening and integrating theoretical perspectives. Human Resource Management Review, 27, 442-457. 
Krausert, A. (2014). HRM systems for knowledge workers: Differences among top managers, middle managers, and professional employees. Human Resource Management, 53, $67-87$.

Kristof-Brown, A.L., \& Stevens, C.K. (2001). Goal congruence in project teams: Does the fit between members' personal mastery and performance goals matter? Journal of Applied Psychology, 86, 1083-1095.

Lai, L., Rousseau, D.M., \& Chang, K.T.T. (2009). Idiosyncratic deals: Coworkers as interested third parties. Journal of Applied Psychology, 94(2), 547.

Liao, C., Wayne, S. \& Rousseau, D.M. (2016) Idiosyncratic deals in contemporary organizations: A qualitative and meta-analytical review. Journal of Organizational Behavior, 37(S1): S9-29.

Las Heras, M., Van der Heijden, B.I.J.M., De Jong, J. \& Rofcanin, Y. (2017). "Handle with care": The mediating role of schedule i-deals in the relationship between supervisors' own caregiving responsibilities and employee outcomes. Human Resource Management Journal, 27, 335-349.

Lepak, D.P., Takeuchi, R. \& Swart, J. (2011). How organizations evaluate and maintain fit of human capital with their needs. In A. Burton-Jones \& J.-C. Spender (eds), Oxford Handbook of Human Capital. Oxford: Oxford University Press, Ch.12.

Leventhal, G. S. (1980). What should be done with equity theory? New approaches to the study of fairness in social relationships. In K. Gergen, M. Greenberg, \& R. Willis (Eds.), Social exchange: Advances in theory and research (pp. 27-55). New York: Plenum.

Liao, C., Wayne, S.J., \& Rousseau, D.M. (2016). Idiosyncratic deals in contemporary organizations: A qualitative and meta-analytical review. Journal of Organizational Behavior, 37(1), 9-29. 
Malik, A.R., \& Singh, P. (2014). 'High potential' programs: Let's hear it for 'B' players. Human Resource Management Review, 24(4), 330-346.

Marescaux, E., De Winne, S. \& Sels, L. (2013). HR practices and affective organizational commitment: (When) does HR differentiation pay off? Human Resource Management Journal, 23, 329-45.

Marescaux, E., De Winne, S. \& Sels, L. (2017). Idiosyncratic deals from a distributive justice perspective: Examining co-workers' voice behavior. Journal of Business Ethics, early view online.

Matzler, K., \& Müller, J. (2011). Antecedents of knowledge sharing-Examining the influence of learning orientation and performance orientation on knowledge sharing. Journal of Economic Psychology, 32, 317- 329.

McDonnell, A., Collings, D., Mellahi, K. \& Schuler, R. (2017). Talent management: A systematic review and future prospects. European Journal of International Management, 11, 86-128.

Michaels, E., Handfield- Jones, H., Axelrod, B., (2001). The war for talent. Harvard Business School Press, Boston, MA.

Mitchell, M. S., Vogel, R. M., \& Folger, R. (2015). Third-parties' reactions to the abusive supervision of coworkers. Journal of Applied Psychology, 100, 1040-1055.

Nerstad, C.G.L., Roberts, G.C., \& Richardsen, A.M. (2013). Achieving success at work: The development and validation of the motivational climate at work questionnaire (MCWQ). Journal of Applied Social Psychology, 43, 2231-2250.

Nerstad, C.G.L., Searle, R., Černe, M., Dysvik, A., Škerlavaj, M., \& Scherer, R. (2017). Perceived mastery climate, felt trust, and knowledge sharing, Journal of Organizational Behavior, early view online. 
Ng, T.W.H., \& Feldman, D.C. (2012). Breaches of past promises, current job alternatives, and promises of future idiosyncratic deals: Three-way interaction effects on organizational commitment. Human Relations, 65, 1463-1486.

Peccei, R., \& van de Voorde, K. (2016). The application of the multilevel paradigm in human resource management-outcomes research. Journal of Management, doi: https://doi.org/10.1177/0149206316673720

Pensgaard, A.M., \& Roberts, G.C. (2002). Elite athletes' experiences of the motivational climate: The coach matters. Scandinavian Journal of Medicine \& Science in Sports, $12,54-59$.

Raudenbush, S.W., \& Bryk, A.S. (2002). Hierarchical Linear Models: Applications and Data Analysis Methods, 2nd edn. Thousand Oaks, CA: SAGE.

Roberts, G. C. (2012). Motivation in sport and exercise from an achievement goal theory perspective: After 30 years, where are we? In G. C. Roberts \& D. Treasure (Eds.), Advances in motivation in sport and excercise, vol. 3: 5-58. Champaign, IL: Human Kinetics.

Roehling, M.V. (2008). An empirical assessment of alternative conceptualizations of the psychological contract construct: Meaningful differences or "much to do about nothing"? Employee Responsibilities and Rights Journal, 20, 261-290.

Rousseau, D.M. (2005). I-Deals: Idiosyncratic Deals Employees Bargain for Themselves. New York: M. E. Sharpe.

Thibault, J., \& Walker, L. (1975). Procedural justice: A psychological analysis. Hillsdale, NJ: Erlbaum.

Vidyarthi, P.R., Liden, R.C., Anand, S., Erdogan, B., \& Ghosh, S. (2010). Where do i stand? Examining the effects of leader-member exchange social comparison on employee work behaviors. Journal of Applied Psychology, 95, 849-861. 
Wang, S., \& Noe, R.A. (2010). Knowledge sharing: A review and directions for future research. Human Resource Management Review, 20, 115-131.

Wason, K.D., Polonsky, M.J., \& Hyman, M.R. (2002). Designing vignette studies in marketing. Australasian Marketing Journal (AMJ), 10(3), 41-58. 
Figure 1. Proposed Model

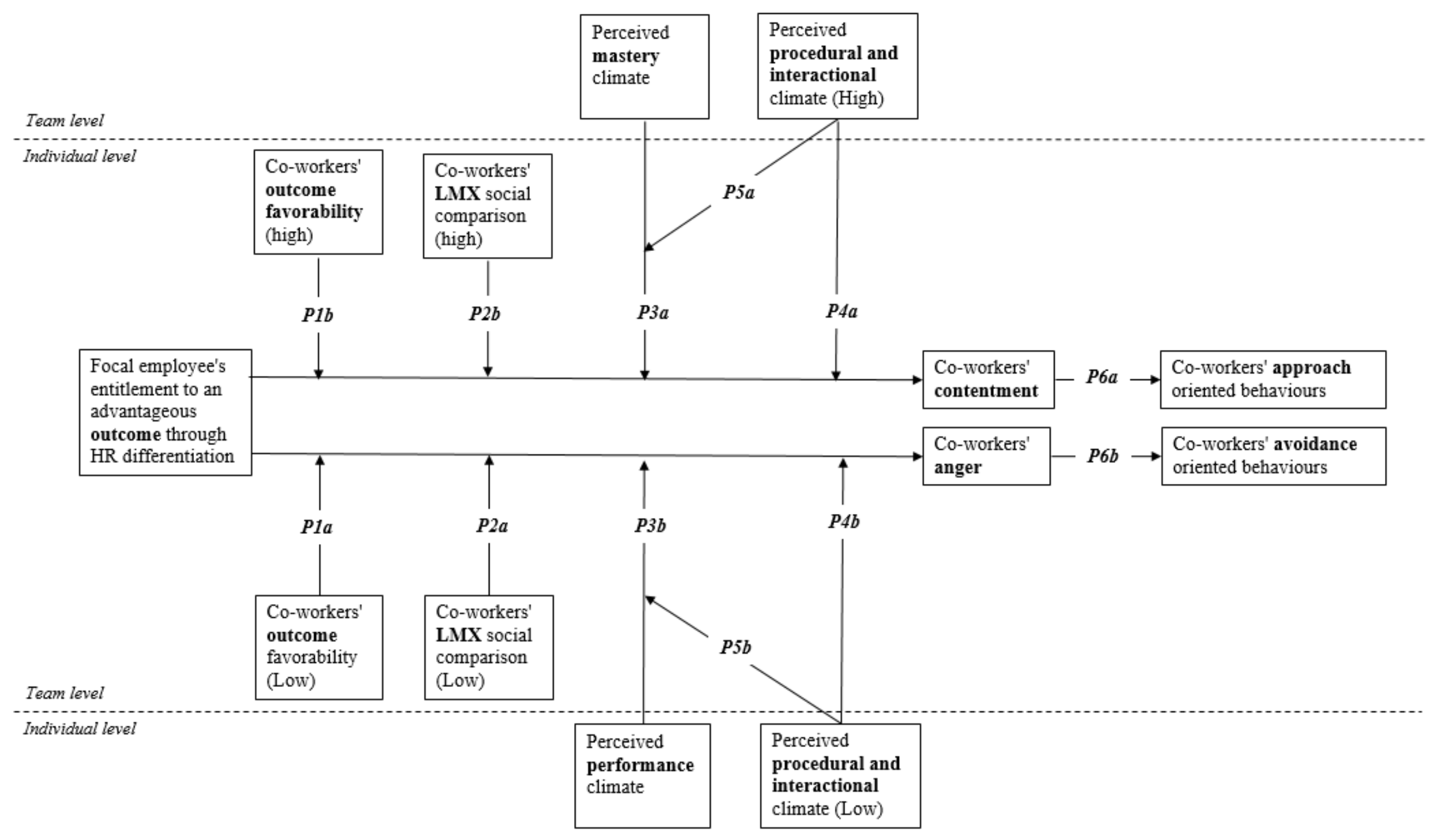

